\title{
Family planning and women's educational advancement in Tehran, Iran
}

\author{
Amir Erfani*
}

\begin{abstract}
This study examines the impact of contraceptive use on women's educational advancement as an indicator of female empowerment, using retrospective data from the 2009 Tehran Fertility Survey. The results show that 15 per cent of married women continued their education after marriage. Also, women using modern contraceptives before a first birth were more likely to experience a 1-2-year increase in education level after marriage, controlling for other factors. Recent cohorts were more likely to continue their education after marriage, especially those who used modern vs. traditional contraceptives. The findings clearly indicate that family planning use after marriage enables women to advance their education by freeing them from reproductive activities.
\end{abstract}

Keywords: educational advancement, family planning, women's empowerment, Iran, Asia.

\section{Résumé}

Au moyen de données rétrospectives du Sondage sur la fertilité de Téhéran de 2009, cette étude examine l'effet de contraceptifs sur l'avancement de l'éducation des femmes en tant qu'indicateur d'autonomisation des femmes. Les résultats ont démontré que 15 pour cent des femmes mariées ont poursuivi leur éducation après mariage. De plus, les femmes qui utilisaient des moyens modernes de contraception avant la naissance de leur premier enfant, comptaient généralement une ou deux années de scolarité de plus après le mariage, tout en contrôlant d'autres facteurs. Des dernières cohortes étaient plus enclines à poursuivre leur éducation après leur mariage, surtout celles qui utilisaient de contraception moderne contre traditionnel. Les conclusions indiquent clairement que la planification familiale après le mariage permet aux femmes d'avancer leur éducation en les libérant des activités reproductrices.

Mots clés : avancement de l'éducation, planification familiale, autonomisation des femmes, Iran, Asie.

\section{Introduction}

Over the last quarter-century many developing countries, including Iran, have undergone a drastic fertility decline after widespread adoption of family planning. The literature documenting this demographic shift has largely focused on investigating the determinants of contraceptive use and the role contraceptives have played in declining fertility rates. In contrast, there has been less research examining the impact of family planning use on women's lives. The research that has been carried out in this area has concentrated on the role of contraceptive use in improving maternal health and

* Amir Erfani, Associate Professor, Department of Sociology, Nipissing University, 100 College Drive, Box 5002, North Bay ON Canada P1B 8L7. Email: amire@nipissingu.ca. 
welfare and child survival, and in preventing HIV infection (for example, see Benagiano 1996; Joshi and Schultz 2007; Robinson and Ross 2007; Smith et al. 2009; Ringheim et al. 2011; Conde-Agudelo et al. 2012). Beyond these well-documented health benefits of family planning, little empirical knowledge is available regarding whether, and to what extent, contraceptive use is an essential ingredient for a more socially rewarding life for women in developing countries. The Women's Studies Project (Hardee-Cleaveland et al. 1996) is a rare systematic attempt to study the impact of family planning on women's lives in developing countries, though the project collected no longitudinal or retrospective data on changes in women's lives resulting from contraceptive use. In addition to its health benefits, the use of available effective contraceptive methods has the potential to enable women to be better poised to take on non-reproductive roles outside the home, including furthering their education (Cleland et al. 2006). As noted by others (Hardee-Cleaveland et al. 1996), a new research agenda is needed to investigate the impact of family planning programs on women in developing nations, beyond their physical health and that of their children.

This study aims to examine the net impact of contraceptive use on women's educational advancement after marriage in Tehran, the capital city of Iran, where fertility has declined rapidly over a short period of time and family planning is widely used, with little unmet need. The study also examines whether the impact of family planning on changes in women's schooling level after marriage varies among different marriage cohorts of women who had been exposed to different levels of access to family planning services over the last three decades.

\section{Research settings}

The Islamic Republic of Iran has experienced perhaps the most rapid and far-reaching fertility decline demographers have ever witnessed. After the 1979 Islamic Revolution, the total fertility rate rose slightly to 7.1 children by the end of 1986, dropped to 4.9 children in 1991 (Statistical Centre of Iran 1999), and then reached below-replacement levels of 2.0 children in 2000 (Erfani and McQuillan 2008) and 1.6 in 2011 (Erfani 2013c). This was accompanied by a rise in contraceptive use among married women, from 37 per cent in 1972 to 65 per cent in 1992 and 74 per cent in 2000 (Aghajanian and Merhyar 1999; Erfani and McQuillan 2008). This is a remarkable fertility transition, given that the government in Iran never resorted to coercive measures, which have been employed elsewhere (e.g., in China). Although the rapid decline in fertility had started in the mid-1980s, the widespread use of contraceptive methods provided by the first post-revolution nationwide family planning program, implemented in 1989, contributed to 63 per cent of the reduction in observed fertility (Erfani and McQuillan 2008). Currently, in 26 out of 31 provinces of Iran the total fertility rate has reached below the replacement level of 2.1 (Erfani 2013c). The capital Tehran has one of the lowest fertility levels in the country, with total fertility estimated at 1.56 children per woman for the city, which contains about one-tenth of the country's population (Erfani 2013a, 2013c). Although the government has recently announced a shift in its population policy to encourage childbearing, evidence shows that any attempts to curb the provision of family planning services are unlikely to raise fertility rates in the country (Erfani 2013b).

The remarkable decline in fertility was accompanied by substantial changes in a number of women's socio-demographic characteristics. Over the past three decades, women's age at marriage increased by three years, from 20 years in 1976 to 23 in 2006. Also, the gender gap in the average age at marriage dropped by 1.4 years in the same period, from 4.4 years in 1976 to 3 in 2006 (Statistical Centre of Iran 2011). 


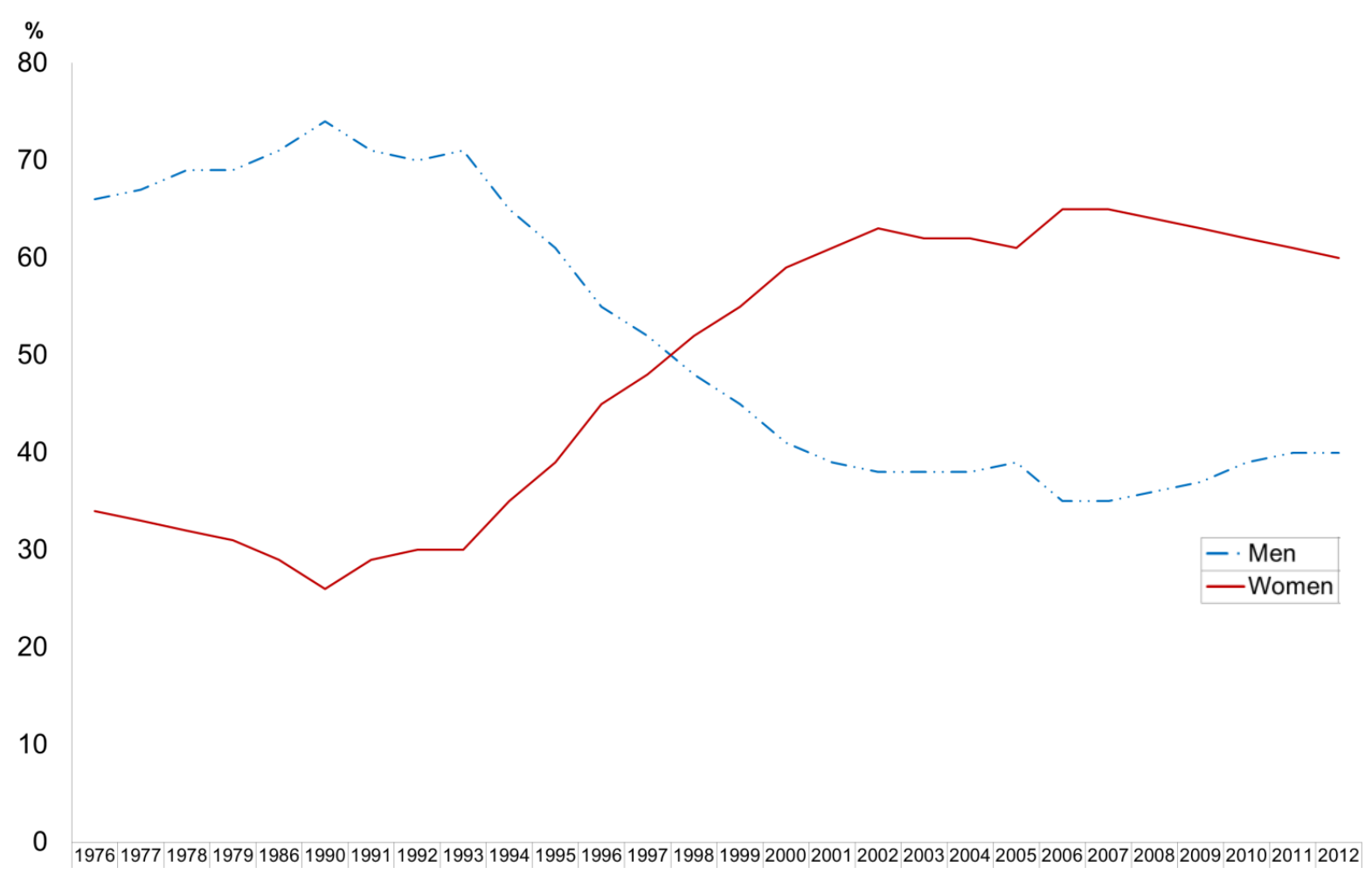

Figure 1. The share of women and men admitted in post-secondary institutions: Iran 1976-2012.

Source: Statistical Centre of Iran (2011) for 1976-1993, IRPHE (2007) for 1994-2007, and NEAO (2012) for 2008-2012.

Alongside the declining trend in fertility, the literacy rates of men and women significantly improved, and the gender gap in education narrowed. The female literacy rate rose from 34 per cent in 1976 to 80 per cent in 2006, and the gender gap in literacy rates shrank considerably, from 28 per cent in 1976 to 8 per cent in 2006 (Statistical Centre of Iran 2011). Moreover, women's educational attainment at the post-secondary level has been remarkable over the past decade. Similar to the patterns observed in OECD countries, including the US, United Kingdom, and Canada (Buchmann et al. 2008: 325; AUCC 2011: 12; OECD 2011), women's enrollment in post-secondary institutions (i.e., colleges and universities) surpassed that of men in 1998 in Iran (see Figure 1). In subsequent years, women maintained their majority on Iranian campuses, reflecting a striking reversal of the gender gap in the proportion of students admitted to colleges and universities, which once favoured males. Women's share of admissions reached its peak (64.5 per cent) in 2007, and has declined slightly since 2008, following a decision of the government to cap the proportion of women's admissions to public post-secondary institutions for varying degrees in certain fields of study (Pour-Abbas 2007).

The striking change in female educational attainment was an important factor in bringing about advancements in the status of women within the family and in society. It is argued that the higher levels of female education after the Islamic Revolution elevated the desire and expectation of women to participate in socioeconomic activity outside the home (Shaditalab 2005). Higher educational levels also changed the perceptions of women regarding their familial and social gender roles (Hoodfar 1996: 34-35). Such a liberal view about female gender roles is prevalent among Iranian girls who "gradually observe and practice democracy within the family," an institution in which "the patriarchal system is diminishing" (Shaditalab 2005: 47, 53). 
The considerable increase in education, however, has not translated into a similar rate of increase in women's labour force participation over the past three decades (Rezai-Rashti 2011), despite a recent study showing that a large number of educated upper- and middle-class women in the affluent northern districts of Tehran were active in the 'informal' market (Etemad Moghadam 2009). After the 1979 Islamic Revolution, the female employment rate dropped from 13 per cent in 1976 to its lowest level, at 8 per cent, in 1986, and then rose slightly, reaching 12.4 per cent in 2006 (Statistical Centre of Iran 2011). There are varying reasons for the low rate of women's labour force participation in Iran. As Rezai-Rashti (2011: 93) argues, one cannot attribute the low women's employment rate in Iran simply to the persistence of a patriarchal culture that restricts women's labour force participation. Among other contributing factors are the nature of Iran's oil-based economy and its young population age structure. The oil-based economy does not require a labour-intensive industrial or service workforce, but rather it is a male and capital-intensive enterprise (Moghadam 2000). Furthermore, it is very difficult for such an economy to provide enough jobs for a large number of individuals under the age of 30, who make up about two-thirds of the country's population (Statistical Centre of Iran 2008).

In the face of limited female employment opportunities in Iran, there is a strong tendency among Iranian women to seek upward social mobility within the family and society, largely through obtaining a higher level of education. This has particularly become a major goal of recent generations of women, who continue their education even after marriage. While not an automatic pathway to enter the labour market, a university degree is advantageous for a woman because it boosts her likelihood of getting married to a man from a higher socioeconomic stratum, bringing more prestige for her within the family and society at large. It also increases her chance of finding a possible job opportunity, whether before or after marriage. Furthermore, many employed Iranian women who are married, especially those working in the public sector, are inclined to continue their education while working, largely for the purpose of income and job promotions. Thus, family planning can help women meet these goals.

However, no hard evidence has yet been provided for women's educational advancement after marriage. Also, no systematic study has yet examined the impact of family planning programs on women's educational advancement after marriage. Clearly, educational advancement, an indicator of women's empowerment, is easier to obtain when women are freed from childbearing by using contraception to prevent an unplanned pregnancy. This study aims to address this gap in the literature by analyzing the impact of family planning use on women's educational advancement after marriage.

\section{Background and hypotheses}

Education is a critical resource for women's empowerment, enabling women "to make strategic life choices" (Kabeer 2001; Malhotra et al 2002). The introduction of modern family planning methods in the United States and Western Europe in the mid-20th century initially aimed to liberate women from unintended pregnancies and enable them to pursue education and to participate in economic activity. In developing countries, organized family planning programs initially sought to slow down rapid population growth. Regardless of the aims, empirical research on the effects of contraceptives has largely focused on the impact of contraceptive use (particularly the pill) on women's education and career choices in the United States rather than in developing countries (Cleland et al. 2006).

The marked changes in the education and employment patterns of American women in the late 1960s and early 1970s were attributed to the "progression toward near-perfect control over childbearing" by improved access to contraception (especially the pill), though a direct causation could not 
be established. Further, it was shown that delayed childbearing enabled women to take advantage of educational opportunities, and made their participation in the labour force easier (Birdsall and Chester 1987). Observing the timing of changes that began in American society during the late 1960s and early 1970s, Goldin and Katz (2000) also suggested that the pill significantly increased American women's age at marriage as well as their participation in professional education and training such as law and medicine. Other scholars showed the positive effects of using contraceptive pills and delaying first birth on the intensity of women's labour force participation and wage growth in the United States (Bailey 2006; Herr 2012). Evidence from European countries also indicated that childbearing impeded educational progression much more than education hampered fertility (Cohen et al. 2011).

Turning to developing countries, to date there has been a dearth of empirical evidence regarding the causal impact of family planning on women's educational advancement. Studies documenting the trends and patterns of fertility declines in developing countries have noted concomitant advancements in women's education along with the declining fertility trends. For instance, in China and some countries in East Asia, such as Singapore and South Korea, where the fertility transition has completed and fertility reached the lowest levels, women's educational levels have increased in the past two decades. Yet it is not clear whether these advancements in women's education are the result of family planning programs or "a continuation of prior government mandated policies requiring greater representation of women in schools" (Malhortara 2009: 11). In Columbia, Miller (2010) found that female teenagers who had access to family planning obtained more years of schooling and were more likely to work in the formal sector. Moreover, some of the women who participated in the Women's Studies Project, a five-year qualitative and quantitative research initiative conducted by Family Health International in ten diverse developing countries (Barnett and Stein 1998; Barnett et al. 1999), declared that family planning allowed them to pursue an education by avoiding an unwanted or mistimed pregnancy. These observations from developing countries are informative, though they hardly indicate a definitive causal effect of family planning on women's educational attainment.

The empirical investigation illustrated in this study is based on a theoretical framework conceptualized by Malhotra (2009). In her paper, she theorized that recent fertility declines observed in middle-income developing countries have the potential to result in "positive and transformative shifts" in several aspects of women's lives, including gender systems, women's well-being, and empowerment at individual and societal levels. She argues that the reduction in fertility that leads to these positive transformations in women's lives depends on contextual factors and on the availability and use of effective family planning services. Drawing on decades of literature in developed countries and observations from developing countries, she argues that increasing the use of effective contraceptives enables women to regulate the timing and number of their births, allowing them "to balance and appropriately time the fulfillment of their sexual, reproductive, and non-reproductive needs and aspirations" (Malhotra 2009: 5). Therefore, the availability and use of effective family planning enables a woman to plan her births and, hence, to spend a larger portion of her lifetime engaging in non-reproductive activities such as education. This study empirically tests this hypothesis in the urban context of Tehran in Iran.

Specifically, this study examines the hypothesis that women who used contraception after marriage to delay childbearing were more likely to pursue their education, compared with those who did not use effective contraceptive methods. Given the dynamics of family planning after the revolution in Iran, the proposed study also examines the assumption that the positive impact of contraceptive use on women's educational attainment has been increasing from older to younger cohorts of women over the last three decades, with increasing access to, and use of, effective modern contraception. 


\section{Data and methods}

The main source of data was the Tehran Survey of Fertility, conducted by the author in August 2009 in the nation's capital. Modelled on a standard Demographic and Health Survey, the study questionnaire was designed to collect a wide range of data, including complete histories of live births and contraceptive use, as well as data on the socioeconomic and demographic characteristics of women and their husbands. Thirty trained and experienced female interviewers collected the data during face-to-face interviews with a representative sample of 2,934 married women aged 15-49 residing in Tehran's 22 residential districts; the response rate was 98 per cent. The sample was selected based on a three-stage stratified cluster random sampling design. The details of the sampling design and survey methods have been described elsewhere (Erfani 2010). The analytical sample in this study includes 2,870 women who were married on or before August 2008, so that there was at least one year between their marriage and the interview (August 2009) to improve their education.

The dependent variable is women's educational advancement, defined as additional years of schooling undertaken by a woman from the date of marriage, when they started living together as husband and wife and hence were exposed to coitus, up to the date of the interview. Therefore, this study does not include women who were in a religious or civil marriage contract, often preceding an official marriage, at the time of the interview. In this study, educational advancement refers to both the 'continuation' of education after marriage among women who left their secondary or post-secondary education incomplete at the time of marriage, and 'progression' to higher levels of post-secondary education after marriage (i.e., Bachelor, Master, or Doctorate). Based on the study hypothesis, this educational advancement occurs after a period of contraceptive use, usually before the date of first birth, by a woman who intends to postpone childbearing. Longitudinal or retrospective data are required in order to assess change in women's educational levels after marriage. Unlike the standard Demographic and Health Surveys, which do not collect retrospective data on women's educational levels at different time points, the Tehran Survey of Fertility collected rich retrospective data on births and contraceptive histories, as well as on the education trajectories of husbands and wives.

The education levels of husbands and wives were measured at two time points: at the time of marriage and at the time of the interview. This allows us to construct the outcome variable educational advancement from the date of marriage, when husband and wife officially wedded and started living together (and hence were exposed to coitus) to the date of the interview (i.e., August 2009). It should be noted that although the survey did not collect data on exact dates when schooling took place after marriage, women's education levels at the date of marriage and at the date of interview were the best available replacements for the dates of schooling after marriage in the survey, as they can capture all women who have improved their education from the time of marriage until the date of interview. Nevertheless, based on our direct observations from the Iranian context, we expect that the educational advancement after marriage usually occurs during the few years right after marriage, before women are engaged in reproductive activities. This is especially the case among younger cohorts of women, who are able to postpone their first birth longer than their older counterparts by using contraceptive methods (Erfani 2013a).

The dependent variable labelled years of woman's educational advancement is constructed by subtracting the women's number of years of schooling at the time of the interview from the number of years of education at the time of marriage. The value of the dependent variable ranges from 0 to 13 years, in which 0 means 'no educational advancement'. As shown later in the Findings section of this paper, women with 1-2 years of educational advancement are qualitatively different from those with 3 or more years of progression in schooling. Therefore, the values of the outcome variable were 
Erfani: Family planning and women's educational advancements in Tehran

grouped into three categories representing the level of educational advancement: '1-2 years', ' 3 or more years', and 'no educational advancement'. However, due to data limitations for multivariate cohort analyses, a binary outcome was developed by collapsing the two categories ' $1-2$ years' and ' 3 or more years' into a new category, with labels 'advancement' versus 'no advancement'. Three multivariate binary logistic models were developed for three marriage cohorts of women. The collapse of the two categories in these models may make it difficult to show separately the effect of contraceptive use on the two levels of educational development across marriage cohorts. However, given the fact that the advancement of schooling by 3 or more years is mostly observed among the oldest cohort of women (this will be shown below in the Findings section), the results of the model related to the oldest cohort (i.e., before 1990) will largely represent '3 or more years' of educational advancement, while the results of the other two models, especially the one associated with the most recent cohort (i.e., 2000-2008), mainly represent the '1-2 years' category of educational advancement.

The temporal order of independent and dependent variables is one of the prerequisites of a causal explanation. Thus, the current study chose theoretically relevant explanatory variables that measured a woman's characteristics for the time before the occurrence of any progress in the woman's educational level. Based on the study hypotheses, stated above, the key explanatory variable consists of 'contraceptive use before the pregnancy of the first birth'. The impact of family planning use before a first birth on the outcome variable was controlled for confounding factors, including age at marriage, spousal age difference, employment status, years of education at marriage, residential districts, and marriage cohorts. To avoid a multicollinearity problem, woman's age and husband's education at marriage were excluded from multivariate analyses.

Based on the first study hypothesis, it is expected that women who have used a modern contraceptive method before the first birth, and hence delayed childbearing longer, are more likely to have advanced their educational level. To examine the second hypothesis, multivariate analyses were conducted separately for three marriage cohorts of women: those who married before 1990, when no official family planning program was in place; cohort 1990-99; and cohort 2000-2008. The cohort analytical strategy allows us to examine the relative impact of contraceptive use before a first birth on women's educational advancement over time. Along with a rise in contraceptive use, especially before a first birth, the increased length of first birth interval (Erfani 2010), and the establishment of pervasive small-family size norms among recent cohorts of women, our general expectation is that the use of family planning before a first birth has a stronger impact on women's educational advancement among the recent cohorts of women.

The gross and net effects of the selected explanatory variables on the outcome variable will be examined by employing binary and multinomial logistic regression models. Where the dependent variables held more than two nominal categories, multinomial logistic regression analyses were applied, and binary logistic regression models were used in the case of a dummy outcome variable. Univariate analyses examined the gross (unadjusted) effect of each covariate on educational advancement, whereas the net (adjusted) effects of one explanatory variable on the dependent variable were examined by multivariate analyses.

\section{Findings}

Table 1 illustrates the socioeconomic and demographic characteristics of married women living in the city of Tehran. The per cent distributions of the sample by the selected characteristics indicate that the majority (65 per cent) used a contraceptive method before becoming pregnant with their first child. Consistent with findings from recent studies (Erfani 2012), the use of traditional methods (largely 
Table 1. Percentage distribution of married women by years of educational advancement, according to selected socioeconomic and demographic covariates: Tehran 2009.

\begin{tabular}{|c|c|c|c|c|c|}
\hline \multirow[b]{2}{*}{ Covariates } & \multicolumn{3}{|c|}{ Years of educational advancement } & \multicolumn{2}{|c|}{ Sample } \\
\hline & None & $1-2$ years & $3+$ years & $\mathrm{N}$ & $\%$ \\
\hline \multicolumn{6}{|c|}{ Contraceptive method used before pregnancy of the 1 st birth } \\
\hline None & 87.1 & 5.2 & 7.7 & 1,019 & 35.5 \\
\hline Any modern & 80.8 & 12.7 & 6.5 & 693 & 24.1 \\
\hline Any traditional & 84.4 & 7.9 & 7.7 & 1,158 & 40.4 \\
\hline \multicolumn{6}{|c|}{ Employment status before 1 st birth } \\
\hline Unemployed & 86.4 & 6.5 & 7.1 & 2,430 & 84.7 \\
\hline Employed & 74.1 & 16.8 & 9.1 & 440 & 15.3 \\
\hline \multicolumn{6}{|c|}{ Years of schooling at marriage } \\
\hline$<12$ & 85.0 & 6.0 & 9.0 & 1,157 & 40.3 \\
\hline 12 & 88.6 & 5.1 & 6.3 & 1,193 & 41.6 \\
\hline$>12$ & 73.8 & 19.8 & 6.3 & 520 & 18.1 \\
\hline \multicolumn{6}{|c|}{ Husband years of schooling at marriage } \\
\hline$<12$ & 90.4 & 3.6 & 6.0 & 1,151 & 40.1 \\
\hline 12 & 85.3 & 7.5 & 7.2 & 1,051 & 36.6 \\
\hline$>12$ & 73.1 & 16.9 & 10.0 & 668 & 23.3 \\
\hline \multicolumn{6}{|l|}{ Age } \\
\hline $15-29$ & 85.6 & 10.0 & 4.4 & 699 & 24.4 \\
\hline $30-39$ & 83.5 & 9.0 & 7.5 & 1,190 & 41.5 \\
\hline $40-49$ & 84.9 & 5.7 & 9.4 & 981 & 34.1 \\
\hline \multicolumn{6}{|l|}{ Age at marriage } \\
\hline$<20$ & 84.0 & 6.7 & 9.3 & 1,282 & 44.7 \\
\hline $20-24$ & 84.3 & 8.9 & 6.8 & 1,152 & 40.1 \\
\hline $25+$ & 86.5 & 10.1 & 3.4 & 436 & 15.2 \\
\hline \multicolumn{6}{|c|}{ Spousal age difference (years) } \\
\hline$<4$ & 85.8 & 8.5 & 5.7 & 953 & 33.2 \\
\hline $4-6$ & 82.9 & 9.4 & 7.7 & 919 & 32.0 \\
\hline $7+$ & 84.7 & 6.6 & 8.7 & 998 & 34.8 \\
\hline \multicolumn{6}{|l|}{ Residential district } \\
\hline Northern & 78.6 & 11.5 & 9.9 & 730 & 25.4 \\
\hline Central & 85.1 & 8.3 & 6.6 & 1,260 & 43.9 \\
\hline Southern & 88.5 & 5.0 & 6.5 & 880 & 30.7 \\
\hline \multicolumn{6}{|l|}{ Marriage cohorts } \\
\hline$<1990$ & 83.9 & 5.5 & 10.6 & 989 & 34.5 \\
\hline 1990-1999 & 84.3 & 8.7 & 7.0 & 1,015 & 35.4 \\
\hline $2000-2008$ & 85.3 & 10.5 & 4.2 & 866 & 30.2 \\
\hline Total & 84.5 & 8.1 & 7.4 & 2,870 & 100 \\
\hline \multicolumn{6}{|c|}{$\begin{array}{l}\text { Notes: Chi-square tests for bivariate relationships between all covariates and years of educational advancement in Table } 1 \\
\text { were statistically significant at P-value }=0.01 \text {. }\end{array}$} \\
\hline \multicolumn{6}{|c|}{$\begin{array}{l}\text { withdrawal) before the first birth was almost two times greater than the use of modern contraceptives } \\
\text { ( } 40 \text { per cent vs. } 24 \text { per cent). Other findings in Table } 1 \text { show that one-quarter resided in better-off com- } \\
\text { munities located in the northern districts of Tehran, while the others lived in the central or southern } \\
\text { districts. The majority of women at the time of the interview were in their mid-reproductive years (age } \\
\text { 30-39), and about half of the women ( } 45 \text { per cent) were under the age of } 20 \text { at the time they married. } \\
\text { It is notable that a significant proportion of women ( } 15 \text { per cent) married at the age of } 25 \text { or older. The } \\
\text { sample was evenly divided between the three categories of spousal age difference. While } 33 \text { per cent of } \\
\text { women had less than four years of age difference with their husbands, } 35 \text { per cent married a man who }\end{array}$} \\
\hline
\end{tabular}


Erfani: Family planning and women's educational advancements in Tehran

marriage cohorts, which represent three groups of married women with diverse life-course experiences related to family formation and childbearing, including contraceptive use.

Generally, 98 per cent of married women were literate (data not shown). At the time of their marriage, 40 per cent had less than 12 years of schooling, a similar proportion (42 per cent) had completed high school, and about one-fifth of the women had some post-secondary education. A relatively similar pattern of educational levels was observed for their husbands. Moreover, data on women's educational advancement indicate that the education level of the majority of women (85 per cent) did not change from marriage to the time of interview, whereas 8 per cent of women completed 1-2 years of schooling after marriage, and another 7 per cent improved their schooling by 3 or more years. Despite overall high levels of educational attainment, the majority (85 per cent) of women in the sample were unemployed.

Socioeconomic and demographic differentials in the level of educational advancement among married women in Tehran are also presented in Table 1. The results show that women who had either some post-secondary education or less than a high school diploma at the time of marriage were more likely to experience an educational advancement compared to those with a high school diploma. However, the proportion of women who attained an educational advancement was greater among those with post-secondary schooling at marriage rather than those with less than a high school diploma at marriage. That is, one-fourth of women with some post-secondary education at the time of marriage improved their education after marriage (largely by 1-2 years), whereas about one-sixth of women with less than a high school diploma at marriage obtained an educational advancement after marriage (largely by more than 2 years).

Other findings indicate that the proportion of women with 1-2 years of educational advancement was greater among those who were employed and had a husband with some post-secondary education, married at age 25 or older, had less than 7 years of spousal age difference, and resided in the northern districts. Interestingly, women with 3 or more years of educational advancement had mostly married before age 20 , with a less educated husband, and had 7 or more years of spousal age difference.

\section{Cohort variations in educational advancement}

Further results indicate significant cohort differentials in women's educational advancement levels and socio-demographic characteristics. Table 1 shows that when moving from older to younger marriage cohorts of women, an educational advancement of 1-2 years jumps from 5.5 per cent among women who married before 1990 to 10.5 per cent among those who married in 2000-2008. In contrast, the proportion of women with 3 or more years of schooling advancement drops by 63 per cent when moving from older to younger marriage cohorts (from 10.6 per cent before 1990 to 4.2 per cent in 2000-2008). The cohort variations in the selected socio-demographic variables in Table 2 provide us with further insights into why the level of educational advancement is different among older and the most recent marriage cohorts of women.

Table 2 illustrates that the use of contraceptives during the period after marriage and before the pregnancy of the first birth increases from 45 per cent among women who married before 1990 to 67 and 84 per cent for the 1990-99 and 2000-2008 marriage cohorts, respectively. Though the use of traditional contraceptive methods (mainly withdrawal) was systematically greater than use of modern methods, the pace of increase in the use of modern versus traditional methods differed significantly across the marriage cohorts. That is, the use of traditional methods before the pregnancy of the first child increased sharply, from 29 per cent in the oldest cohort to 43 per cent in the 1990-99 cohort, 
Table 2. Percentage distribution of contraceptive use before first birth, median first birth interval, mean age at marriage, and mean years of schooling at marriage among married women of reproductive ages by marriage cohort: Tehran $2009(\mathrm{n}=\mathbf{2 , 8 7 0})$.

\begin{tabular}{|c|c|c|c|c|c|c|}
\hline \multirow[b]{2}{*}{ Marriage cohorts } & \multicolumn{3}{|c|}{$\%$ contraceptive use before first birth } & \multirow{2}{*}{$\begin{array}{l}\text { Median first } \\
\text { birth interval } \\
\text { (months) }\end{array}$} & \multirow{2}{*}{$\begin{array}{l}\text { Mean age at } \\
\text { first marriage }\end{array}$} & \multirow{2}{*}{$\begin{array}{l}\text { Mean years } \\
\text { of schooling } \\
\text { at marriage }\end{array}$} \\
\hline & None & $\begin{array}{l}\text { Modern } \\
\text { methods }\end{array}$ & $\begin{array}{c}\text { Traditional } \\
\text { methods }\end{array}$ & & & \\
\hline Before 1990 & 55 & 16 & 29 & 18.0 & 17.9 & 08.5 \\
\hline 1990-1999 & 33 & 22 & 45 & 23.0 & 20.8 & 10.8 \\
\hline $2000-2008$ & 16 & 37 & 47 & 28.0 & 22.6 & 12.3 \\
\hline
\end{tabular}

whereas a sharp increase in the use of modern methods occurred after 1990, from 22 per cent among women in the 1990-99 cohort to 37 per cent among those who married during 2000-2008.

Along with increasing contraceptive use before the first birth, the median length of the first birth interval (i.e., duration from marriage to first birth) increased from 18 months among older cohorts of women to more than 3 years among the most recent marriage cohort. Similarly, the mean age at first marriage and mean years of schooling increased by 21 per cent and 31 per cent, respectively, from the oldest cohort to the most recent marriage cohort of women (see Table 2).

The cohort results clearly show that despite similar percentages of women (about 15 per cent) with some years of educational advancement across the three marriage cohorts, as illustrated in Table 1, women with 1-2 years of educational advancement are qualitatively different from those obtaining 3 or more years of educational advancement. That is, the proportion of women with more than 2 years of educational advancement is greater among the older cohort (before 1990) of women who were less likely to use contraceptive methods before a first birth and hence began childbearing soon after marriage, and mostly married early before the age of 20, with incomplete secondary education. In contrast, women with 1-2 years of educational advancement are mostly from younger cohorts of women who largely married after the age of 20, with some post-secondary education, and delayed childbearing for more than 3 years by using contraceptive methods. Variations in the levels of educational advancement in the study sample and among the cohorts will be further examined by analysing the net effects of the covariates on changes in women's schooling.

\section{Multivariate analyses}

Table 3 presents both the univariate estimates for categories of a given covariate and multivariate estimates or net effects for categories of a given variable, after controlling for the effects of other variables. The results show that the use of modern or traditional contraceptive methods before the first birth played a significant role in the advancement of women's education by 1-2 years. After controls in the second model, the use of a traditional method had no effect on the likelihood of educational advancement by 1-2 years, but relative to women who were not using any method before the first birth, those who were using a modern method were 84 per cent more likely to advance their education by 1-2 years rather than have no advancement. In contrast, among women with more than 2 years of educational advancement, family planning use before the pregnancy of the first birth had no significant effect.

The findings related to the control variables show socioeconomic characteristics of women with different levels of educational advancement. There are systematic effects related to women's employment before a first birth, with greater likelihood of educational advancement among employed than unemployed women. The net effects of employment status in the full model indicate that compared with unemployed women, those who were employed before their first birth were 1.7 and 2.1 times more likely to obtain an additional 1-2 years or more than 2 years of schooling, respectively, rather 
Erfani: Family planning and women's educational advancements in Tehran

Table 3. Relative risk ratios from multinomial logistic regression model assessing associations between selected covariates and advancement in women's education by "1-2" and " $3+$ years" in relative to "no educational advancement" among currently married women in Tehran, Iran 2009 ( $\mathrm{n}=\mathbf{2 , 8 7 0 )}$.

\begin{tabular}{|c|c|c|c|c|c|c|}
\hline \multirow[b]{3}{*}{ Covariates } & \multicolumn{3}{|c|}{$1-2$ years } & \multicolumn{3}{|c|}{$3+$ years } \\
\hline & \multirow{2}{*}{ Univariate } & \multicolumn{2}{|c|}{ Multivariate } & \multirow{2}{*}{ Univariate } & \multicolumn{2}{|c|}{ Multivariate } \\
\hline & & Model I & Model II & & Model I & Model II \\
\hline \multicolumn{7}{|c|}{ Contraceptive method used before pregnancy of the 1st birth } \\
\hline None & 1.00 & - & 1.00 & 1.00 & - & 1.00 \\
\hline Any modern & $2.63 * * *$ & - & $1.84 * *$ & 0.91 & - & 1.22 \\
\hline Any traditional & $1.58^{* *}$ & - & 1.29 & 1.04 & - & $1.34+$ \\
\hline \multicolumn{7}{|c|}{ Employment status before 1st birth } \\
\hline Unemployed & 1.00 & 1.00 & 1.00 & 1.00 & 1.00 & 1.00 \\
\hline Employed & $3.00^{* * *}$ & $1.74 * *$ & $1.73 * *$ & $1.50^{*}$ & $2.10^{* * *}$ & $2.11 * * *$ \\
\hline \multicolumn{7}{|c|}{ Years of schooling at marriage } \\
\hline$<12$ & 1.00 & 1.00 & 1.00 & 1.00 & 1.00 & 1.00 \\
\hline 12 & 0.82 & $0.70+$ & $0.65^{*}$ & $0.67 * *$ & $0.67 *$ & $0.65^{*}$ \\
\hline$>12$ & $3.83 * * *$ & $2.87 * * *$ & $2.56^{* * *}$ & 0.81 & 0.88 & 0.84 \\
\hline \multicolumn{7}{|l|}{ Age at marriage } \\
\hline$<20$ & 1.00 & 1.00 & 1.00 & 1.00 & 1.00 & 1.00 \\
\hline $20-24$ & $1.33+$ & $0.72+$ & 0.73 & $0.73 *$ & 0.87 & 0.87 \\
\hline $25+$ & $1.46^{*}$ & $0.43 * * *$ & $0.44 * *$ & $0.36^{* * *}$ & $0.39 * *$ & $0.40 * *$ \\
\hline \multicolumn{7}{|c|}{ Spousal age difference(years) } \\
\hline$<4$ & 1.00 & 1.00 & 1.00 & 1.00 & 1.00 & 1.00 \\
\hline $4-6$ & 1.14 & 1.17 & 1.19 & $1.41+$ & 1.24 & 1.27 \\
\hline $7+$ & 0.79 & 0.84 & 0.87 & $1.56^{* *}$ & 1.24 & 1.26 \\
\hline \multicolumn{7}{|l|}{ Residential district } \\
\hline Northern & $2.59 * * *$ & $1.86^{* *}$ & $1.75^{* *}$ & $1.71 * *$ & $1.74 * *$ & $1.71 * *$ \\
\hline Central & $1.73 * *$ & $1.55^{*}$ & $1.49^{*}$ & 1.06 & 1.10 & 1.08 \\
\hline Southern & 1.00 & 1.00 & 1.00 & 1.00 & 1.00 & 1.00 \\
\hline \multicolumn{7}{|l|}{ Marriage cohorts } \\
\hline$<1990$ & 1.00 & 1.00 & 1.00 & 1.00 & 1.00 & 1.00 \\
\hline 1990-1999 & $1.58^{* *}$ & $1.41+$ & 1.32 & $0.66^{* *}$ & 0.76 & $0.73+$ \\
\hline $2000-2008$ & $1.89 * * *$ & $1.47+$ & 1.27 & $0.39 * * *$ & $0.49 * *$ & $0.46^{* * *}$ \\
\hline
\end{tabular}

Notes: (ref.) $=$ reference category. $+<0.10,{ }^{*} \mathrm{p} \leq 0.05,{ }^{* *} \mathrm{p} \leq 0.01,{ }^{* * *} \mathrm{p} \leq 0.001$.

than have no advancement. This suggests that women who worked before their first birth may see how important education is for their job and income promotions, and hence they are more motivated to obtain more education relative to unemployed women. They may also think that the additional education could give them an advantage in seeking employment after they have children.

The direction of the effect of women's education level at marriage on the probability of having an educational advancement differed among the two groups of women with different levels of educational advancement. In contrast with women whose schooling at marriage was less than a high school diploma, and consistent with bivariate results, those with some post-secondary education at the time of marriage were 2.6 times more likely to improve their education by $1-2$ years after marriage, while the likelihood of increasing education levels by more than 2 years was greater among women with incomplete secondary schooling at marriage. There were also differences according to the respondents' residential district. The net effect of residential district in the full model indicates that compared with women living in the southern districts, those who resided in the northern districts of Tehran were 1.8 times more likely to improve their education by 1-2 years, or by more than 2 years, rather than have no advancement. 
Regarding the effect of age at marriage, the univariate results show that compared to women who married before the age of 20, those who married after the age of 20 were more likely to obtain a 1-2year educational advancement, and less likely to advance their education by 3 or more years. However, after controlling for other covariates, age at marriage was inversely associated with both levels of educational advancement. That is, compared with women who married before the age of 20 , those who married at the age of 25 or older were 56 and 60 per cent less likely to attain 1-2, or more than 2, years of educational advancement, respectively, rather than no advancement. Furthermore, the net effect of spousal age difference on women's educational advancement was not significant, though univariate analyses indicated that relative to women with less than 4 years of spousal age difference, those with 4-6 years and those with 7 or more years of a spousal age gap were 41 and 56 per cent more likely to improve their education by 3 or more years, respectively, rather than have no advancement.

The pattern of educational advancement is different among marriage cohorts of women. The univariate results show that the more recent marriage cohorts of women (i.e., 1990-1999 and 20002008) were more likely to obtain 1-2 years of educational advancement, whereas women who married before 1990 were more likely to improve their education by 3 or more years. Even after controlling for different variables, the same pattern of educational advancement by marriage cohorts remained. Nevertheless, the cohort differentials in educational advancement by 1-2 years shrank after controlling for the effect of contraceptive use (1.41 and 1.47 in Model I vs. 1.32 and 1.27 in

Table 4. Odds ratios for logistic regression models predicting advancement over no advancement in women's education during the period from marriage to the date of interview (August 2009) among currently married women in different marriage cohorts, Tehran 2009.

\begin{tabular}{|c|c|c|c|c|c|c|}
\hline \multirow[b]{3}{*}{ Covariates } & \multicolumn{6}{|c|}{ Marriage cohorts } \\
\hline & \multicolumn{2}{|c|}{ Before 1990} & \multicolumn{2}{|c|}{$1990-1999$} & \multicolumn{2}{|c|}{$2000-2008$} \\
\hline & Univariate & Multivariate & Univariate & Multivariate & Univariate & Multivariate \\
\hline \multicolumn{7}{|c|}{ Contraceptive method used before pregnancy of the 1st birth } \\
\hline None & 1.00 & 1.00 & 1.00 & 1.00 & 1.00 & 1.00 \\
\hline Any modern & 1.34 & 1.35 & $1.66^{*}$ & 1.31 & $3.71 * * *$ & $2.96 * *$ \\
\hline Any traditional & 1.04 & 1.05 & $1.67 * *$ & $1.55^{*}$ & $2.29 * *$ & $2.00+$ \\
\hline \multicolumn{7}{|c|}{ Employment status before 1st birth } \\
\hline Unemployed & 1.00 & 1.00 & 1.00 & 1.00 & 1.00 & 1.00 \\
\hline Employed & $3.72 * * *$ & $4.77 * * *$ & $2.39 * * *$ & $1.75^{*}$ & $1.71 * *$ & 1.15 \\
\hline \multicolumn{7}{|c|}{ Years of schooling at marriage } \\
\hline$<12$ & 1.00 & 1.00 & 1.00 & 1.00 & 1.00 & 1.00 \\
\hline 12 & $0.73+$ & $0.46^{* * *}$ & 0.79 & $0.61 *$ & 1.00 & 0.93 \\
\hline$>12$ & $2.34 *$ & 0.87 & $2.66 * * *$ & $1.86^{*}$ & $2.60 * * *$ & $2.49 * *$ \\
\hline \multicolumn{7}{|l|}{ Age at marriage } \\
\hline$<20$ & 1.00 & 1.00 & 1.00 & 1.00 & 1.00 & 1.00 \\
\hline $20-24$ & 0.76 & 0.74 & 1.11 & 0.89 & 1.27 & 0.72 \\
\hline $25+$ & 0.40 & 0.30 & 0.90 & $0.45^{*}$ & 1.08 & $0.49 *$ \\
\hline \multicolumn{7}{|c|}{ Spousal age difference(years) } \\
\hline$<4$ & 1.00 & 1.00 & 1.00 & 1.00 & 1.00 & 1.00 \\
\hline $4-6$ & 1.42 & 1.38 & 1.46 & $1.55+$ & 0.95 & 0.92 \\
\hline $7+$ & 1.33 & 1.26 & 1.18 & 1.17 & 0.77 & 0.81 \\
\hline \multicolumn{7}{|l|}{ Residential district } \\
\hline Northern & 1.00 & 1.00 & 1.00 & 1.00 & 1.00 & 1.00 \\
\hline Central & 0.73 & 0.70 & $0.56^{* *}$ & $0.64 *$ & 0.67 & 0.86 \\
\hline Southern & $0.52 * *$ & $0.46 * *$ & $0.37 * * *$ & $0.47 * *$ & $0.57 *$ & 0.96 \\
\hline Number of women & 989 & & 1,015 & & 866 & \\
\hline
\end{tabular}

Notes: (ref.) $=$ reference category. $+<0.10,{ }^{*} \mathrm{p} \leq 0.05,{ }^{*} \mathrm{p} \leq 0.01,{ }^{* * *} \mathrm{p} \leq 0.001$. 
Erfani: Family planning and women's educational advancements in Tehran

Model II), whereas the corresponding cohort differentials did not change significantly among women with 3 or more years of educational advancement. Cohort variations in women's educational advancement are further examined below.

The results in Table 4 show that the (gross and net) effect of contraceptive use before the first birth on women's educational advancement was only significant among women who married after 1990, with greater effects among women in the 2000-2008 marriage cohort. In particular, multivariate results, associated with the most recent marriage cohort (i.e., 2000-2008) show that relative to women who did not use any contraceptive methods before the first birth, those who used a modern or a traditional contraceptive method were 3.0 and 2.0 times more likely, respectively, to improve their education. It is notable that the net effect of modern contraceptive methods on women's educational advancement was significant only among women in the 2000-2008 marriage cohort.

Among the control variables in Table 4, the multivariate results on women's schooling at marriage show that women with some post-secondary education in the 1990-1999 and 2000-2008 marriage cohorts were 1.9 and 2.5 times more likely, respectively, to have an educational advancement, compared to those with incomplete secondary education at marriage. In contrast, among the women in the oldest marriage cohort (i.e., before 1990), those with incomplete secondary education at marriage were more likely to experience an educational advancement. Moreover, the net effect of employment status on educational advancement was greatest among the oldest cohort of women, where employed rather than unemployed women were 4.8 times more likely to attain an educational advancement, after controlling for other variables. A similar but weaker effect existed in the 1990-1999 cohort of women, but not in the most recent cohort. Similarly, the effect of residential districts on women's educational advancement was not significant among the most recent marriage cohort. The other results in Table 4 are either non-significant or consistent with the results that were found among all women in the sample.

\section{Discussion and conclusions}

This research investigated the gross and net impacts of family planning use on the level of women's educational advancement after marriage, in a representative sample of married women aged 15-49 living in the city of Tehran. This study attempted to find out whether contraceptive use before the first birth frees a woman from reproductive activities by delaying childbearing, and hence allows her to continue her education after marriage. A cohort approach was utilized to compare the impact of family planning across different marriage cohorts of women who were exposed to different degrees of contraceptive availability and hence had different patterns of use.

The descriptive results show that 15 per cent of married women continued their education after marriage, of which 8 per cent advanced their schooling by 1-2 years, and 7 per cent attained 3 or more years of educational advancement. Women who had some post-secondary schooling or less than a high school diploma at the time of marriage were more likely to improve their education after marriage. Women with some post-secondary education at marriage were more likely to advance their education by 1-2 years, whereas those with less than a high school diploma at marriage largely attained more than 2 years of educational advancement. These results clearly suggest that a sizable proportion of women who married before completing their secondary or post-secondary education could pursue their education after marriage.

Multivariate analyses show that contraceptive use before the first birth was strongly associated with 1-2 years of educational advancement, whereas it had no significant effect on women's educational 
advancement by more than 2 years. The differing effect of family planning can be due to the fact that, according to the cohort descriptive results, women with more than 2 years of educational advancement had married early (before the age of 20), with some incomplete secondary education, and entered into motherhood soon after marriage. They are largely women of the oldest cohort, who did not delay childbearing long after marriage. Based on the authors' observations, these women most likely improved their education after reaching their desired number of children and freedom from childbearing activities. In contrast, women with 1-2 years of educational advancement were mostly women from the most recent cohorts, who had married later (after the age of 20) and delayed the first birth by using contraceptives (largely modern methods), which facilitated the advancement of their education. The evidence from this paper suggests that spacing of the first birth by using contraception has been common among the most recent marriage cohort (i.e., 2000-2008) and those with 1-2 years of educational advancement, whereas, as strongly speculated, a proportion of women in the older cohorts most likely used long-term or permanent contraceptive methods after achieving their desired number of children in order to pursue their incomplete education. This speculation is consistent with the fact that the 1989 family planning program affected the childbearing behaviour of all women who had married in different calendar years and had different numbers of children at the time the program was implemented. Therefore, the oldest cohort of women (i.e., before 1990) accessed freely available contraceptive methods after 1989, when they had already given birth to a number of children (including their first birth).

Other multivariate results show that women who were employed rather than unemployed at the time of marriage, and those who had higher levels of schooling at marriage, were more likely to attain an educational advancement. The stronger tendency of employed married women to improve their education after marriage suggests that they may see how important education is for their job and income promotions, and hence they are more motivated than unemployed women to obtain additional education. Moreover, the strong, positive impact of their husbands' post-secondary education in bivariate results suggests the existence of strong male support for women's educational advancement among families with educated husbands.

The results across marriage cohorts show that the use of contraceptive methods before the first birth, and the proportion of women with 1-2 years of educational advancement, increased from the older to the younger marriage cohorts. These results are consistent with recent evidence indicating an increase in first birth intervals in Iran, along with an increase in the proportion of contraceptive users before the first birth (Erfani 2010, 2013a). Also, multivariate cohort analyses reveal an increasing positive impact of modern contraceptive use on women's educational advancement, when moving from the oldest to the youngest cohort of women. This is consistent with our understanding that women of the older cohort, who married before 1990, did not have broad access to freely available contraceptive methods, due to the lack of an official family planning program from 1979 to 1989. Although some contraceptive methods were available to urban women through pharmacies during that period (1979-89), evidence shows that they spent most of their early marital lives in reproductive activities rather than using contraception, either traditional or modern methods (Abbasi et al. 2009: 117), with a very short first birth interval (Erfani and McQuillan 2014). Therefore, the non-significant net effect of contraceptive use before first birth on educational advancement among older cohorts of women is due to the fact that they started childbearing right after marriage, and hence they did not have free time for educational advancement right after marriage. Furthermore, the growth of religious fervour, promoted by the new government after the 1979 Islamic Revolution, encouraged early marriage and childbearing, and the government designed policies offering financial support for larger families (Erfani and Yuksel-Kaptanoglu 2012: 22). 
Other multivariate cohort results indicate that being employed at marriage and living in northern residential districts was associated with a greater likelihood of women's educational advancement across all three marriage cohorts. However, the effect of employment status and residential districts became weaker or non-significant when moving from the older to the younger cohorts. These findings suggest a growing tendency to advance education after marriage among recent cohorts of women, regardless of their employment status and place of residence. The greater likelihood of enhanced schooling among employed women who married before 1990 may be explained by the fact that it was more common for employed rather than unemployed women, with incomplete or lower levels of education, to raise the level of their education for income and job promotion purposes. Yet among recent cohorts it is very common that a woman after marriage, especially before entering into the stage of motherhood, seeks higher levels of education regardless of her employment status. As discussed earlier in this paper, Iranian young women seek upward social mobility within the family and society by enhancing their education, which may also increase their chances of finding a possible job after marriage.

This study faced an important limitation. The data regarding education trajectories did not include dates of when schooling after marriage took place, including in relation to childbearing. Clearly, a more precise measurement of when such schooling took place would have provided more insights into the findings. Nevertheless, they do provide important evidence for the links between education and family planning use.

Fertility control and maternal and child health conventionally have been the prime objectives of family planning programs in developing countries. However, the findings of this study highlight that contraception can play a significant role in improving women's schooling after marriage. Therefore, the provision of family planning services must be seen as an integral element of development policies designed to promote women's social and economic status within their respective societies.

\section{Acknowledgements}

This research was made possible by funding from an Insight Development Grant (430-20110464)of the Social Science and Humanities Research Council of Canada, the Fertility \& Empowerment Network at the International Center for Research on Women (ICRW), the William and Flora Hewlett Foundation, and the Population Studies and Research Center in Asia and the Pacific (Tehran). Earlier versions of this article were presented at the 2012 annual meetings of the Canadian Population Society and Population Association of America, and at the 8th annual PopPov Conference on Population, Reproductive Health, and Economic Development.

\section{References}

Abbasi-Shavazi, M.J., P. McDonald, and M. Hosseini-Chavoshi. 2009. The Fertility Transition in Iran: Revolution and Reproduction. New York: Springer.

Aghajanian, A., and A.H. Merhyar. 1999. Fertility, contraceptive use and family planning program activity in the Islamic Republic of Iran. International Family Planning Perspectives 25(2):98-102.

AUCC (Association of Universities and Colleges of Canada). 2011. Trends in Higher Education: Volume 1 - Enrolment. Ottawa: Association of Universities and Colleges of Canada. http://www.aucc.ca/wpcontent/uploads/2011/05/trends-2011-vol1-enrolment-e.pdf (retrieved November 10, 2011). 
Barnett, B., M. Konate, M. Mbloyi, J. Mutambirwa, M. Francis-Chizororo, M. Taruberekera, and P. Ulin. 1999. The impact of family planning on women's lives: findings from the Women's Studies Project in Mali and Zimbabwe. African Journal of Reproductive Health 3(1):27-38.

Barnett, B., and J.S. Stein. 1998. Women's Voices, Women's Lives: The Impact of Family Planning: A Synthesis of Findings From the Women's Studies Project, Family Health International. Research Triangle Park, NC: Family Health International.

Bailey, M.J. 2006. More power to the pill: The impact of contraceptive freedom on women's life cycle labor supply. Quarterly Journal of Economics 121(1):289-320.

Benagiano, G. 1996. Benefits from family planning services. European Journal of Contraception and Reproductive Health Care 1(3):225-30.

Birdsall, N., and L.A. Chester. 1987. Contraception and the status of women: What is the link? Family Planning Perspectives 19(1):14-18.

Buchmann, G., T.A. DiPrete, and A. McDaniel. 2008. Gender inequalities in education. The Annual Review of Sociology 34:319-37.

Cleland, J., S. Bernstein, A. Ezeh, A. Faundes, A. Glasier, and J. Innis. 2006. Family planning: The unfinished agenda. The Lancet 368(9549):1810-1827.

Cohen, J.E., Ø. Kravdalb, and N. Keilmanb. 2011. Childbearing impeded education more than education impeded childbearing among Norwegian women. PNAS 108(29):11830-11835.

Conde-Agudelo, A., A. Rosas-Bermudez, F. Castaño, and M.H. Norton. 2012. Effects of birth spacing on maternal, perinatal, infant, and child health: A systematic review of causal mechanisms. Studies in Family Planning 43(2):93-114.

Erfani, A. 2010. Tehran Survey of Fertility, 2009: Final Report. Tehran: Population Studies and Research Centre in Asia and Pacific: Ministry of Science, Research, and Technology. [in Persian]

- 2012. Factors associated with the use of withdrawal in Iran: Do fertility intentions matter? Journal of Comparative Family Studies 43(2): 301-312.

- 2013a. Tehran Survey of Fertility Intentions, 2013: Final Report. Tehran: Population Studies and Research Centre in Asia and Pacific: Ministry of Science, Research, and Technology. [in Persian]

- 2013b. A Reversal in the Population Policy of Iran: Do Curbing Family Planning Programs Raise Low Fertility? Paper presented at the $27^{\text {th }}$ meeting of International Union for the Scientific Study of Population (IUSSP). Busan, Republic of Korea (26-31 August).

-2013c. Fertility levels, trends and differentials in Iran and the city of Tehran. Population Studies 1(1): 87-107. [in Persian]

Erfani, A., and K. McQuillan. 2008. Rapid fertility decline in Iran: Analysis of intermediate variables. Journal of Biosocial Science 40(3):459-478.

- 2014. The changing timing of births in Iran: An explanation on the rise and fall in fertility after the 1979 Islamic Revolution. Biodemography and Social Biology 60(1):67-86.

Erfani, A., and I. Yuksel-Kaptanoglu. 2012. The use of withdrawal among birth limiters in Iran and Turkey. Studies in Family Planning 43(1):21-32.

Etemad Moghadam, F. 2009. Undercounting women's work in Iran. Iranian Studies 42(1):81-95. 
Erfani: Family planning and women's educational advancements in Tehran

Goldin, C., and L.F. Katz. 2000. Career and marriage in the age of the pill. The American Economic Review (Special Issue: Papers and Proceedings of the One Hundred Twelfth Annual Meeting of the American Economic Association 90(2):461-465.

Hardee-Cleaveland, K., P. Ulin, P. Pfannenschmidt, and C. Visness. 1996. The Impact of Family Planning and Reproductive Health on Women's Lives : A Conceptual Framework. Working Paper 96-02. Research Triangle Park, NC: Family Health International.

Herr, J.L. 2012. Measuring the effect of the timing of first birth. Working Paper, University of Berkeley, Department of Economics. http://emlab.berkeley.edu/users/webfac/moretti/e251_f12/herr.pdf (retrieved October 15, 2012).

Hoodfar, H. 1996. Bargaining with fundamentalism: Women and the politics of population control in Iran. Reproductive Health Matters 4(8):30-40.

IRPHE (Institute of Research and Planning in Higher Education). 2007. The Statistics of Higher Education. Tehran: Institute of Research and Planning in Higher Education, Ministry of Science, Technology, and Higher Education. http://www.irphe.ir/FA/Statistics/Gozide.aspx (retrieved October 10, 2012). [in Persian]

Joshi, S., and P. Schultz. 2007. Family Planning as an Investment in Development: Evaluation of a Program's Consequences in Matlab, Bangladesh. Center Discussion Paper No. 95 (New Haven, CT: Yale University Economic Growth Center). http://www.econ.yale.edu/ pschultz/ConsolidatedMatlab103106.pdf (retrieved December 15, 2011).

Kabeer, N. 2001. Reflections on the measurement of women's empowerment. In Discussing Women's Empowerment: Theory and Practice. SIDA: Swedish International Development Cooperation Agency.

Malhotra, A. 2009. Remobilizing the Gender and Fertility Connection: The Case for Examining the Impact of Fertility Control and Fertility Declines on Gender Equality. Paper presented at the IUSSP Meetings, Marrakech, Morocco (September 28).

Malhotra, A., S.R. Schuler, and C. Boender. 2002. Measuring Women's Empowerment as a Variable in International Development. Workshop on Poverty and Gender: New Perspectives: World Bank. http://siteresources.worldbank.org/INTGENDER/Resources/MalhotraSchulerBoender.pdf (retrieved October 8, 2012).

Miller, G. 2010. Contraception as development? New evidence from family planning in Colombia. The Economic Journal 120:709-736.

Moghadam, V. 2000. Women's socioeconomic participation and Iran's changing political economy. In The Economy of Iran: The Dilemmas of an Islamic State, edited by P. Alizadeh. New York: I.B. Tauris, pp. 233-260.

NEAO (National Education Assessment Organization). 2012. The statistics of participants in the university entrance exams who were admitted to post-secondary institutions, 2008-2012. Journal of Paike Sanjesh 701-702. [in Persian]

OECD (Organization for Economic Cooperation and Development). 2011. Education and training statistics: new entrants by sex and age. http://stats.oecd.org/Index.aspx?DatasetCode=RGRADSTY (retrieved November 1, 2011).

Pour-Abbas, A. 2007. The gender share of student admissions in Iran's colleges and universities. DonyaE-Eqtesad Daily No. 1468, p. 8. 
Rezai-Rashti, G. 2011. Iranian women's increasing access to higher education but limited participation in the job market. Middle East Critique 20(1):81-96.

Ringheim, K., J. Gribble, and M. Foreman. 2011. Integrating family planning and maternal and child health care: Saving lives, money, and time. Policy Brief. Washington: Population Reference Bureau. http://www.prb.org/pdf11/ familyplanning-maternal-child-health.pdf (retrieved December 20, 2011).

Robinson, W.C., and J.A. Ross (eds.). 2007. The Global Family Planning Revolution: Three Decades of Population Policies and Programs. Washington: The World Bank.

Shaditalab, J. 2005. Iranian women: Rising expectations. Critique: Critical Middle Eastern Studies 14(1):3555.

Smith, R., L. Ashford, J. Gribble, and D. Clifton. 2009. Family Planning Saves Lives. 4th edn. Washington Population Reference Bureau. http://www.prb.org/pdf09/familyplanningsaveslives.pdf (retrieved October 7, 2012).

Statistical Centre of Iran. 1999. Population Indicators of Iran: 1956-96. Tehran: Statistical Centre of Iran. - 2008. The 2006 National Census. Tehran: Statistical Centre of Iran. [in Persian] - 2011. Statistical Year Books, 1978-2007. Tehran: Statistical Centre of Iran. http://amar.sci.org.ir/ (retrieved November 10, 2011). [in Persian] 